TI 2002-117/3

Tinbergen Institute Discussion Paper

New Evidence of the Effect of

Transaction Costs on Residential

Mobility

Jos van Ommeren'

Michiel van Leuvesteijn²

I Faculty of Economics and Business Administration, Vrije Universiteit Amsterdam, and Tinbergen Institute,

2 CPB Netherlands Bureau for Economic Policy Analysis, The Hague. 
Tinbergen Institute

The Tinbergen Institute is the institute for economic research of the Erasmus Universiteit Rotterdam, Universiteit van Amsterdam and

Vrije Universiteit Amsterdam.

Tinbergen I nstitute Amsterdam

Keizersgracht 482

1017 EG Amsterdam

The Netherlands

Tel.: +31.(0)20.5513500

Fax: $\quad+31 .(0) 20.5513555$

Tinbergen Institute Rotterdam

Burg. Oudlaan 50

3062 PA Rotterdam

The Netherlands

Tel.: $\quad+31 .(0) 10.4088900$

Fax: $\quad+31 .(0) 10.4089031$

Most TI discussion papers can be downloaded at

http://www.tinbergen.nl 


\title{
New evidence of the effect of transaction costs on residential mobility
}

\author{
$15 / 11 / 02$
}

\author{
Jos van Ommeren ${ }^{*}$ \\ Free University, FEWEB, De Boelelaan, 1081 HV Amsterdam The Netherlands \\ Email: jommeren@feweb.vu.nl \\ Michiel van Leuvensteijn \\ CPB Netherlands Bureau for Economic Policy Analysis, P.O. Box 80510 \\ 2508 GM The Hague, The Netherlands \\ Email:mvl@cpb.nl
}

*) The authors would like to thank Statistics Netherlands for providing access to the IPR data. Jos van Ommeren is affiliated to the Tinbergen Institute, Keizersgracht 482, 1017 EG Amsterdam, The Netherlands. 


\section{New evidence of the effect of transaction costs on residential mobility}

Abstract. Transaction costs have attracted considerably attention in the theoretical literature on residential mobility. In many European countries, these costs mainly consist of ad-valorem transaction costs. In the current paper, we demonstrate empirically for the Netherlands that the transaction costs have a strong negative effect on the owners' probability of moving. Under a range of different specifications, it appears that a one percent-point increase in the value of transaction costs - as a percentage of the value of the residence - decreases ownership to ownership residential mobility rates by eight percent. The estimates imply that ownership to ownership mobility rates would be 50 percent higher in the absence of the current six percent ad-valorem buyer transaction tax. Our estimates are consistent with the observation that in the Netherlands ad-valorem transaction costs mainly consist of buyer transaction costs.

JEL:R200, C410, D190; keywords: moving costs, residential mobility and transaction taxes 


\section{Introduction}

Theoretical and empirical studies have shown that transaction costs in the housing market may create lock-in effects. ${ }^{1}$ The negative welfare effects of transaction costs are thought to be substantial, due to sub-optimal consumption of housing (O'Sullivan et al., 1995), a reduction in job mobility and potentially increasing unemployment (Oswald, 1997, 1999, Van Ommeren et al., 2000). These transaction costs include transaction taxes, such as capital gains taxes and ad-valorem taxes which are proportional to the house value (e.g. stamp duties and sales taxes). Buyer ad-valorem taxes are common in the OECD housing market. In most OECD countries, purchasers of residential homes have to pay registration taxes, socalled stamp duties, which are essentially ad-valorem buyer taxes ranging from 0 and 12 percent (Robinson, 1988). For example, in the Netherlands, the buyer has to pay a tax equal to $6 \%$ of the value of the property. In addition to ad-valorem taxes, purchasers usually pay brokerage fees, mortgage fees and recording fees (solicitor). These fees are also 36 proportional to the property value. They typically amount to 4 to 6 percent of the property value. The total monetary transaction costs (the sum of the taxes and the fees) in the Netherlands are about 12 percent of the property value, approximately 50 percent of average net annual income (OECD, 1999). As far as we are aware, no empirical evidence on the size of the lock-in effects of ad-valorem costs / taxes has been provided. ${ }^{2}$

Despite the lack of evidence on the lock-in effect of ad-valorem transaction costs, information on average residential mobility rates of owners and ad-valorem transaction costs of European countries suggests a strong negative effect of these costs on residential mobility (see Appendix 1). For example, in the United Kingdom, transaction costs are much lower, and residential mobility rates are much higher than in other European countries. However, transaction costs mainly consist of tax rates which are set by national governments, conditional on the average residential mobility rate, so the causal relationship between transaction costs and residential mobility cannot be easily investigated using aggregate information.

The current paper aims to estimate the effect of transaction costs on residential mobility using micro-economic data. We are able to identify the effect of transaction costs on owners' residential mobility by using information on the effect of the property value on the propensity to move to ownership and the propensity to move to renting.

\footnotetext{
${ }^{1}$ Weinberg et al., 1981; Venti and Wise, 1989; Rouwendal and Meijer, 2001.

${ }^{2}$ Lundberg and Skedinger (1999) provide evidence regarding the effects of capital gains taxes for Sweden.
} 
The outline of the paper is as follows. In Section 2, we discuss the theoretical considerations to estimate the effect of transaction costs on residential mobility of owners employing information on the relationship between the property value and residential mobility. In Sections 3 and 4, the statistical model and the data are introduced. In Section 5, we present and interpret the results. Section 6 concludes.

\section{Theory}

\subsection{Basic Model}

Following the literature on the optimal number of residential moves (e.g. Amundsen, 1985; Englund, 1985; Hardman and Ioannides, 1985), we assume that a residential move is not initiated by abrupt changes of any kind, but is the result of long-term consumption planning, based on evaluations of permanent income, anticipated changes in household composition, etc. So, we assume that households have perfect foresight. We follow the literature by assuming the existence of moving costs. Given the household's income, the price of housing services and other goods, the household's objective is to determine the optimal residence duration and the optimal consumption of housing services (and other goods). One of the main results in the literature on the optimal number of moves is that the optimal residence duration depends positively on the moving costs. Moreover, the residence duration does not depend on the consumption of housing services, because both have been optimally chosen (Amundsen, 1985). Because residence duration is inversely related to the probability of moving residence, it follows that the probability of moving residence, $\mathrm{P}$, depends negatively on the moving costs $\mathrm{m}$ and does not depend directly on the property value, V. So:

$$
P=f(m, V)=f(m) ; \frac{\partial P}{\partial m}<0 ; \frac{\partial P}{\partial V}=0
$$

The above result can be readily extended with the introduction of tenure, so households may choose between renting and ownership. Because the residence duration is optimally chosen, the probability of moving residence does not depend on the value of the residence. So:

$$
P^{o}=f\left(m^{o}\right) \quad \text { and } \quad P^{r}=g\left(m^{r}\right),
$$


where the superscript $\mathrm{i}(\mathrm{i}=\mathrm{o}, \mathrm{r})$ denotes whether the household moves to ownership or to renting.

Let us now focus on owners and let us distinguish between different components of moving costs. In case of a move to renting, total moving costs, $\mathrm{m}^{\mathrm{r}}$, consist of a fixed component and a component which varies with the value of the current residence, because of costs associated with selling (mainly estate agent costs):

$$
m^{r}=\alpha+\beta V \quad \alpha, \beta>0
$$

where $\alpha$ captures the fixed non-monetary and monetary costs of moving costs of moving residence. ${ }^{3}$ In the current study, we initially fix the value of $\beta$. This value has been obtained by noting that most households sell their residences via estate agents and that in the Netherlands the market for real estate agents is highly regulated. In the Netherlands, the organisation for real estate agents set the estate agent costs at $1.85 \%-2.0 \%$ of the value of the property sold. ${ }^{4}$ Moving house involves a few other costs that are related to the size of the property and therefore to property value (e.g. transportation costs), so initially we fix $\beta$ to $3.0 \%$. Later on, we will estimate $\beta$.

In case of a move to ownership, the transaction costs, $\mathrm{m}^{\mathrm{o}}$, encompass the costs paid by households which move to renting and the buyer costs, which are proportional to the value of the next residence:

$$
\mathrm{m}^{\mathrm{o}}=\alpha+\beta V+\not V^{N} \quad \alpha, \beta, \gamma>0,
$$

where $\mathrm{V}^{\mathrm{N}}$ denotes the value of the next residence. The assumption of perfect foresight implies that the value of $\mathrm{V}^{\mathrm{N}}$ is known to the household. Buyer costs in the Netherlands involve taxes $(6 \%)$, estate agent costs (1.85-2.0\%), registration costs and, usually, mortgage and valuer's fees. So, the buyer costs typically vary between 8 and 10\%. In the current study, we will initially fix $\gamma$ to $9 \%$, but we will also estimate $\gamma$ (relative to $\beta$ ). Note that $\mathrm{V}^{\mathrm{N}}$ is only observed for a sample of households which move during the period of observation. We make therefore use of the relationship between $\mathrm{V}^{\mathrm{N}}$ and $\mathrm{V}$, and estimate this relationship using observations for which $\mathrm{V}^{\mathrm{N}}$ is observed. We suppose a linear relationship between $\mathrm{V}^{\mathrm{N}}$ and $\mathrm{V}$ :

\footnotetext{
${ }^{3}$ Van Vuuren (2002) estimates $\alpha$ and obtains large values for $\alpha$ in the Netherlands.

${ }^{4}$ Only recently, in 2001, this practice has been outlawed.
} 
$V^{N}=\delta+\eta V+\varepsilon$

where $\varepsilon$ is random error. ${ }^{5}$ Combining the last two equations, we obtain the following relation between $\mathrm{m}^{\mathrm{o}}$ and $\mathrm{V}$ :

Recall that the theoretical model implies that $\mathrm{V}$ has no direct effect on $\mathrm{P}^{\mathrm{o}}$ and $\mathrm{P}^{\mathrm{r}}$. Equations

$m^{o}=\alpha+\delta \gamma+(\beta+\eta \gamma) V+\gamma \varepsilon$

(2) and (5) imply that:

$P^{o}=f\left(m^{o}(V)\right) \quad$ and $\quad P^{r}=g\left(m^{r}(V)\right)$.

It follows that:

$\frac{\partial P^{o}}{\partial m}=\left(\frac{\partial m^{o}}{\partial V}\right)^{-1} \frac{d P^{o}}{d V}=\frac{1}{\beta+\eta \gamma} \frac{d P^{o}}{d V}$

and

$\frac{\partial P^{r}}{\partial m}=\left(\frac{\partial m^{r}}{\partial V}\right)^{-1} \frac{d P^{r}}{d V}=\frac{1}{\beta} \frac{d P^{r}}{d V}$.

The values of $d P^{o} / d V$ and $d P^{r} / d V$ will be estimated given information on residential moving behaviour and the value of the residence. Hence, given information on the values of $\beta$ and $\gamma$ and estimates of $\eta$ (which can be estimated given information on $\mathrm{V}^{\mathrm{N}}$ and $\mathrm{V}$ ), we are able to identify the marginal effect of moving costs on residential mobility.

One empirical difficulty is that in the Netherlands the value for $\beta$ is small, which makes the estimate of $\partial P^{r} / \partial m$ extremely sensitive to assumptions on $\beta$. For example, the assumption

\footnotetext{
${ }^{5}$ One expects that $\delta>0$ and $0<\eta<1$, because households tend to increase the consumption of housing services at the beginning and tend to decrease this consumption at the end of their housing career (e.g. Amundsen, 1985).
} 
that $\beta$ obtains values between $2 \%$ and $3 \%$, implies that it varies by a factor of 1.5 due to uncertainty about the value of $\beta$. Note further that if households perceive $\beta$ to be close to zero, then this implies that $d P^{r} / \mathrm{d} V=0$, so our estimation procedure cannot identify $d P^{r} / d m$. In conclusion, estimates of $\partial P^{o} / \partial m$ are plausibly more reliable than estimates of $\partial P^{r} / \partial m$, since the latter are very sensitive to values of $\beta$. When $\beta$ approaches zero, $\partial P^{r} / \partial m$ is not identified. To overcome this empirical difficulty, we will also attempt to estimate $\beta$.

\subsection{Estimating $\beta$}

Up to now, we have assumed that $\beta$ and $\gamma$ are known. Another attempt is to estimate $\beta$ relative to $\gamma$, by imposing stronger behavioural assumptions. We will suppose that:

$$
\frac{\partial P^{r}}{\partial m}=\frac{\partial P^{o}}{\partial m}
$$

This assumption, which we will test, implies that the marginal effect of the moving costs on mobility to ownership is equal to the effect on mobility to renting. ${ }^{6}$ This assumption is in line with previous empirical studies that estimate the effect of moving costs on residential mobility (Lundborg and Skedinger, 1998; Venti and Wise, 1984). Using equations (7), (8) and (9), it appears that:

$$
\frac{\beta}{\gamma}=\frac{\eta \frac{d P^{r}}{d V}}{\frac{d P^{o}}{d V}-\frac{d P^{r}}{d V}}
$$

and

$$
\frac{\partial P^{r}}{\partial m}=\frac{\partial P^{o}}{\partial m}=\frac{\frac{d P^{o}}{d V}-\frac{d P^{r}}{d V}}{m}
$$

So, we are able to identify the ratio of $\beta$ to $\gamma$, but not $\beta$ and $\gamma$ separately. Given information on $\gamma$, one does not need any information on $\beta$. Alternatively, when one has information on the sum of $\beta$ and $\gamma$ (the total ad-valorem tranaction costs), one can estimate both $\beta$ and $\gamma$.

\footnotetext{
${ }^{6}$ Studies for the United States indicate that this assumption may be inaccurate (e.g. Haurin and Grill, 2002), because an increase in moving costs may be positively related to an increase in future moving costs which decreases expected residential mobility. A decrease in expected residential mobility makes owning relatively more attractive (Boehm, 1981). For the Netherlands, this assumption is thought to be more accurate because the difference in residential mobility rates of owners and renters is much smaller in the Netherlands than in the United States. Moreover, the correlation between current and future moving costs may be moderate.
} 


\subsection{Relaxing the assumption of perfect foresight}

The assumption of perfect foresight implies that the probability of moving does not depend directly on the value of the residence. This assumption may not always hold. For example, households may not foresee abrupt changes in relevant factors such as income, household composition, interest rates and house prices etc (see Quigley, 1987). One may argue of course that households are perfectly rational in an uncertain environment (e.g. Haurin and Grill, 1987), so, on average, given risk neutrality the value of the residence should have no effect on the probability of moving. We prefer however to make a less restrictive assumption and will assume that the value of the residence directly influences residential mobility. Such an assumption allows for example for the possibility that, given uncertainty about future income, risk averse households initially consume less housing services than desired in the absence of uncertainty. At the moment that the household receives more information on future income, the household will, on average, consume more housing services, which suggests a direct negative effect of V. So, we will relax equation (1) by assuming:

$P^{o}=f\left(m^{o}(V), V\right) \quad$ and $\quad P^{r}=g\left(m^{V}(V), V\right)$.

We make now the assumption that $\partial P^{r} / \partial V=\partial P^{o} / \partial V$. This assumption can be justified by noting that the value of the current residence should not determine the choice of the next residence type of tenure (conditional on income, savings, housing services, preferences, etc.). Further, we maintain the assumption that $\partial P^{r} / \partial m=\partial P^{o} / \partial m$.

Given these assumptions, we obtain again equation (10) and (11). For convenience, we have summarised the assumptions and the theoretical effect of moving costs on the probability of moving residence in Table 1.

Table 1 over here 
Following the literature, we have presumed that a moving household chooses the type of tenure (ownership or renting) optimally. Although this assumption may be realistic for most moves, this assumption may be inaccurate for some households. For example, in the United States households that sell their residence and migrate to another region may fail to find in time a residence which offers the desired housing consumption, and move temporarily to renting. In this case, households move to renting anticipating to pay buyer costs in the near future, so buyer costs will have a negative effect on moves to renting. Such an example is, however less plausible for the Netherlands, because of the geographical size of the country. Migration over long distances is absent in the Netherlands, and households are therefore informed about local housing markets.

Furthermore, we have assumed that households choose the residence duration optimally taking moving costs into account. Although this may be true for most households, it is likely that when a divorce is the main reason for moving, a move may become 'forced' and moving costs may become irrelevant for the probability of moving. ${ }^{7}$ To test this idea, we will later on distinguish between moves to renting and moves to renting which are not followed by a move to ownership shortly after the move.

\section{Empirical Models}

\subsection{Estimation of $d P^{o} / d V, d P^{r} / d V$ and $\beta$}

In this paper we use hazard rate models or - stated differently - duration models to estimate the impact of the residence value on residential mobility. The hazard rate is defined as the rate at which an event takes place over a short period of time, given that this event has not occurred so far (Ginsberg, 1979a; 1979b). All results derived above for the probability to move also apply to residential hazard rates. In our empirical application, the time interval dt is set to one year. Two types of transitions are explicitly modelled: transitions within the owner sector and transitions from ownership to renting. Therefore, the hazard rate to move is modelled into two possible 'competing risks'. Other transitions (such as moves to housing for the elderly) are here accounted as incomplete spells. The variable b denotes the index of a particular risk ( $\mathrm{b}=$ "o" or " $\mathrm{r}$ "). The hazard rate, $\theta^{\mathrm{b}}$, measures the probability of leaving a residence to state $\mathrm{b}$ over a specific (small) time interval $[\mathrm{T}, \mathrm{T}+\mathrm{dt}]$, given that one occupies this residence up to $\mathrm{T}$ :

\footnotetext{
${ }^{7}$ Households that move to renting and within a short period back to ownership belong more likely to a group of 'forced' movers.
} 
$\theta^{\mathrm{b}}=\operatorname{Pr}\left(\mathrm{T}<\mathrm{t}_{\mathrm{b}}<\mathrm{T}+\mathrm{dt} \mid\right.$ all $\left.\mathrm{t}_{\mathrm{b}} \geq \mathrm{T}\right)$.

The competing risks are assumed to have a proportional (or loglinear) structure (see e.g. Lancaster, 1990). Thus, the risk into $b$ at time $t_{b}$ can be described as:

$\theta^{b}\left(t_{b} \mid X\right)=h_{b}\left(t_{b}\right) \exp \left[\psi_{b} X\right]$

where $h_{b}(t)$ denotes the baseline hazard, which is a function of the elapsed duration $t_{b}, X$ is a matrix representing individual characteristics and $\psi_{\mathrm{b}}$ is a vector of regression parameters to be estimated. We estimate this model using a partial likelihood approach to estimate $\psi_{\mathrm{b}}$ accounting for uncompleted spells (Clark and Dieleman, 1996; Lancaster, 1996).

\subsection{Estimation of $\eta$}

We estimate the relationship between the anticipated value of the future residence and the value of the current residence by regressing the value of the next residence, which is observed for a selective sample of households, on the current value of the residence and other explanatory variables used in the hazard model. In line with the theoretical specification (see (4)), we assume a linear model. ${ }^{8}$

\section{Data}

In the present study, we make use of the IPR database. The IPR (Income Panel Research) database consists of a sample of about 75000 Dutch households that are followed yearly by tax authorities, over the period 1990-1997. In the IPR, a number of possible housing states are distinguished. Moving behaviour can be derived from address changes. Housing market states consist of rental housing, homeownership, or other types (for example, housing for the elderly). From this sample we select households that moved to ownership (16090 observations) between 1990 and 1996. We follow these households over time from the moment of the first move to ownership until the year of the next move. So, we analyse a flow sample. For each household, we observe a complete (when the household moves before the

\footnotetext{
${ }^{8}$ We also estimate this model correcting for sampling bias using the Heckman correction method following Edin and Englund (1991). This correction method implies that one first estimates the probability to select an observation using a probit model on the whole sample of observations. In the next step, the (inverse) Mill's ratio is included which corrects for the selectivity bias in the selected sample (Maddala, 1983). However, correcting for sampling bias generates identical results
} 
end 1997) or incomplete spell (when the household does not move before the end of 1997), together with various individual characteristics of one adult member of the household (the head or the partner) at the beginning of the spell. ${ }^{9}$ For almost 14 percent of the observations, we observe completed spells (a move to renting or to ownership). ${ }^{10}$

Our dependent variable is the duration of the spell distinguishing between moves to renting and moves to ownership. Explanatory variables include characteristics of the household, such as age, gender, having a partner who earns income, or not. Further, dummies are created for the number of persons in a household (one or two persons or more) and whether the residence is located in urban areas. Financial indicators are used for household income (in logs) and wealth (savings more than 13,636 euro per adult in the household) and financial characteristics of the residence: value of the mortgage, value of the residence. ${ }^{11}$ The value of the residence is equal to the WOZ-value, which is the value as described in the Law on Property. ${ }^{12}$ Regional dummies are used to correct for differences in local housing markets (we distinguish 40 regions, so called COROP regions). Finally, yearly dummies are included. Note that all financial indicators are real (1990 prices) using the consumer price index deflator. Descriptive variables can be found in Table 2.

\section{Table 2 over here}

\section{Table 3A and B over here}

\subsection{Empirical Results}

\footnotetext{
${ }^{9}$ The IPR does contain an usual high proportion of 'movers' within the first year, which are mainly administrative corrections in addresses, so moves within the first year are censored. This procedure has also another rationale, because households that who move within 6 months after moving to ownership receive full reimbursement of the buyer tax which is the main component of the transaction costs.

${ }^{10}$ Our data indicate that households are about twice as likely to move to renting than to ownership (see Table 2). Data based on stock samples for the Netherlands suggest that the probability of moving to renting and the probability of moving are about equal (Clarke and Dieleman, 1996). Note that in a flow sample, the elapsed duration is much shorter than in stock samples, and that households with short spells are more likely to move to renting (see Dieleman et al., 1995). Moreover, many moves to renting are within a short period followed by moves to ownership (see 5.3) It is well known that the stock sample procedures tend to underestimate short spells.

${ }^{11}$ One guilder is about one dollar.

${ }^{12}$ The WOZ-value tends to be slightly lower than the purchase price, implying that our estimates of the effect of transaction costs are plausibly slightly higher than reported in the current paper.
} 
In this section, we discuss the effect of transaction costs on residential mobility rates in the Netherlands combining information from a competing risks residential hazard model (see Table 3) and a regression model of property values of residences (see Table 4). The effect of transaction costs on residential mobility is measured by using the estimated effects of the value of the residence on the moving rate to ownership and to renting and the relationship between the value of the next residence and the current residence. Because the effect of the value of the residence on residential mobility plays a fundamental role in the estimation procedure, we have experimented with a linear (Table 3A) and a loglinear specification (Table 3B) for the value of the residence in the competing risks residential hazard model.

\section{Table 4 over here}

The estimates in Tables $3 \mathrm{~A}$ and $\mathrm{B}$ indicate that the value of the current residence has a negative effect on the probability of moving to ownership, but has a less (according to the loglinear model) or no (according to the linear model) effect on the probability of moving to renting. This can be interpreted as evidence that ad-valorem buyer costs have a strong negative effect on the decision to move to ownership, whereas the effect of the seller transaction costs is small. ${ }^{13}$

It is worthwhile to discuss briefly the effect of the other explanatory variables in Tables $3 \mathrm{~A}$ and $\mathrm{B}$. The results indicate that income of the household has a strong positive influence on the likelihood of moving into another owned residence, but has no effect on the likelihood of moving into renting. ${ }^{14} \mathrm{We}$ interpret this result as evidence that owning is more attractive for high-income households, which may be explained in a number of ways. The main reason is plausibly that the Dutch tax regime makes ownership more attractive for high-

\footnotetext{
${ }^{13}$ Ioannides and Kan (1996) find only weak evidence of a negative effect of property value on residential mobility in the US suggesting that transaction costs are not proportional to the property value. In the US, total transaction costs are much lower than in the Netherlands due to the absence of ad valorem transaction taxes. Consequently, the effect of property values on residential mobility to ownership must be much smaller in the US than in the Netherlands when we presume that the marginal effect of transaction costs in the US are the same as in the Netherlands (see equation 7). Moreover, it seems plausible that the marginal effect of transaction costs on residential mobility is lower (in absolute sense) in the US than in the Netherlands, on average, for example because households are risk averse and transaction costs are much higher in the Netherlands. A statistical explanation would be that in the current study the number of observations is much larger than in the study of Ioannides and Kan (1996).

${ }^{14}$ This result corresponds with the study of Gronberg and Reed (1990), which does not distinguish between moves to ownership and renting, which find that household income has a positive effect on residential mobility of owners.
} 
income households. Moreover, these households are less likely to receive financial assistance in the renting market and are less restricted in receiving a mortgage, because of the ability to pay for the mortgage prepayment (Quigley, 1987; Pinto, 2002). The latter interpretation is consistent with the estimates of the effect of the two wealth variables (wealth dummy, ratio of mortgage value to property value), which indicate that wealthy households are more likely to move into another owned residence, but less likely to move into renting. Findings of Henderson and Ioannides (1987) confirm these results. We find also that persons with an employed partner are more likely to move to ownership, confirming the results of Gronberg and Reed (1990) for married couples and Ihlanfeldt and Silberman (1985) for two-earner households. Females are more likely to move to renting, which is in line with findings of Ihlanfeldt and Silberman (1985). Households within urban environments are more likely to move residence. High residence values in the region increase mobility to ownership, but not to renting. The latter result has many interpretations, and is consistent with the matching model of Wheaton (1990) that predicts a positive relationship between the residence values and residential mobility.

The results of the regression of the value of the next residence on the value of the current residence, shown in Table 4, indicate that the coefficient associated with current value of the residence, previously denoted as $\eta$, is equal to 0.58 . The estimates imply that households that live in residences of low value tend to move to more expensive residences space (vertical mobility); households that live in residences of average value tend to move to residences of similar value (horizontal mobility), whereas households that live in residences of high value tend to move to cheaper accommodation (end of the career moves). Note that the value of the current residence is the most important predictor of the value of the next residence justifying equation (4). The effects of other explanatory variables also make sense. In line with the residential expenditure literature, income and wealth have positive effects on the value of the (next) residence, where as the effect of age is non-monotonic (e.g. Ioannides and Rosenthal, 1994; Charlier et al., 2000; 2001).

\section{Table 5 over here}

Combining the results from Table 3 and 4, we are able to calculate the effect of transaction costs on the residential moving rate. One convenient measure is how much a one 
percent-point increase in the transaction costs (e.g. from 10 to 11 percent, about 870 euros on average) increases the (competing risks) residential mobility rate. Given the linear specification, $\partial \log \theta^{o} / \partial(m / V)=\psi_{0} V /(\beta+\eta \gamma)$ and $\partial \log \theta^{r} / \partial(m / V)=\psi_{r} V / \beta$. Given the loglinear specification, $\partial \log \theta^{o} / \partial(m / V)=\psi_{0} /(\beta+\eta \gamma)$ and $\partial \log \theta^{r} / \partial(m / V)=\psi_{r} / \beta$.

Presuming that the marginal effects to ownership and renting are the same, the $\partial \log \theta / \partial(m / V)$ can be easily derived using (11). In Table 5, the effects of a one percent-point increase in the transaction costs on the percentage change in the (competing risk) residential mobility rate can be found. ${ }^{15}$ The different specifications indicate that a one percent point increase in the ad-valorem transaction costs rate tend to decrease residential mobility by 8.05 to $12.66 \%$. Given the range of specifications, the variation in these estimates is remarkably small. The estimates are plausible in the light of international aggregate data on residential mobility and transaction costs (see Appendix 1). ${ }^{16}$ The results from specification 1 suggest that transaction costs have a stronger negative effect on moves to renting than to ownership (in line with theoretical and empirical studies such as Boehm, 1981, Rosenthal, 1988; Haurin and Grill, 2002). Nevertheless, the null-hypothesis that the effects on moves to renting and on moves to ownership are of equal size cannot be rejected (the mean difference is equal to $3.90 \%$ with a standard error of $2.48 \%$ according to the loglinear specification; given the linear specification the effect of transaction costs on moves to renting is not identified, so we cannot test the hypothesis). This result is seemingly in contrast to the studies by Boehm (1981), Rosenthal (1988) and Haurin and Grill (2002). Note however that these studies are based on mobility behavior in the United States, where renters are four times more likely to move than owners. In contrast, in the Netherlands, renters are only twice as likely to move (Everaers and Davies, 1993). Because the expected residence duration difference is much smaller for the Netherlands than for the United States, the effect of transaction costs on the choice of tenure must also be considerable smaller. This may explain why the difference in the effects on moving to renting and to ownership is absent (or too small to detect) in the Netherlands. ${ }^{17}$ Hence, given the results from specifications, we can safely employ the assumption that $\partial P^{o} / \partial m=\partial P^{r} / \partial m$, which justifies the use of specification 2 .

\footnotetext{
15 The standard errors have been calculated using the delta method, see Goldberger (1991).

${ }^{16}$ The international data suggest that a percent-point increase in transaction costs decreases residential mobility by 8 percent (see Appendix 1). Note that the aggregate data do not allow us to distinguish between moves to ownership and to renting, so this estimate is effectively much higher. This estimate is likely an overestimate due to the endogeneity of transaction taxes (which are the main component of transaction costs) which are set by the national government.
} 
Recall that the main advantage of specification 2 is that it does not rely on assumptions of $\beta$, and enables one to estimate $\beta$ (given $\gamma$ ). Given the linear specification, the estimate of $\beta$ appears to be $0.061 \%$ and not statistically different from zero. This estimate is unreasonably low for the Netherlands, as the estate agents costs of selling already amounts to (at least) $1.85 \%$. This suggests that the linear model is misspecified. We have therefore used an encompassing test that is appropriate to apply to testing non-nested hypotheses (Mizon and Richard, 1986). The encompassing test shows that for moves to owning the loglinear model is statistically superior to the linear model. The encompassing test implies that the linear and loglinear specification of the residence value is included in the model. Using a standard LRtest, one can than test whether general model (with both specifications) is statistically superior to the restricted model (with one specification). In case of moving to owning, the general model does not reject the loglinear specification $\left(\operatorname{LR}(1)=0.166, \chi^{2}(1)=3.84\right)$, but rejects the linear specification $\left(\operatorname{LR}(1)=27.89, \chi^{2}(1)=3.85\right)$ at the 5 percent level. In case of moving to renting, the encompassing test is inconclusive. Hence, from an economic perspective ( $\beta$ is too low) and statistical point of view (the encompassing test), the loglinear model is preferred.

For the latter model, $\beta$ is estimated to be equal to $3.7 \%$ (standard error $0.5 \%$ ) using the formula in Table 1. Such an estimate is plausible for the Netherlands. Hence, $\gamma /(\beta+\gamma)$ is equal to 0.71 . Thus, the estimates are consistent with the notion that ad-valorem transaction costs mainly consist of costs associated with selling. Furthermore, the results indicate that the total ad-valorem transaction costs rate is equal to $12.7 \%$ (measured as $\beta+\gamma$ ), which is close to estimates for the Netherlands (OECD, 1999).

\subsection{Sensitivity analysis}

For the loglinear specification, a one percent-point increase in transaction costs decreases residential mobility by $8.05 \%$ (standard error $1.39 \%$ ). Although the latter estimate is the most reliable estimate (from an economic and statistical view), we emphasize that this result is robust with respect to the chosen specification of the residential mobility hazard rate model (linear versus loglinear). Equation (10) indicates however that this estimate may be sensitive to the chosen and respectively estimated values of $\gamma$ and $\eta$.

\footnotetext{
${ }^{17}$ We will show later on that if we consider only a subset of moves to renting, our results confirm the studies of Boehm (1981), Rosenthal (1988) and Haurin and Grill (2002).
} 
Let us focus first on $\gamma$. We have presumed that $\gamma$ is equal to 0.09 , but its exact value is plausibly somewhere between 0.08 and $0.10 .{ }^{18}$ The implication is that the point estimate may vary between $-7.15 \%$ and $-9.01 \%$. So, the estimate is quite insensitive with respect to the chosen value of $\gamma .^{19}$

Second, let us focus on $\eta$. This coefficient has been estimated by regressing the value of the next residence on the value of the current residence, controlling for a number of explanatory variables. Employing a range of specifications, the estimate of 0.58 is insensitive to the inclusion of the Heckman correction, which corrects for selective sampling, and other explanatory variables. For example, including the Heckman correction, the coefficient is only slightly higher and is equal to 0.59 . When we include the explanatory variable, $\eta$ is equal to $0.56 .^{20}$

Further, we have experimented with different functional forms for equation (4). Again the results are quite robust. For example, if we specify both the current and the next property value in logarithms $\partial \theta / \partial(m / V)$ is close to $-7 \%$. Next, we have experimented whether $\eta$ interacts with age, the idea being that the stage of the lifecycle may determine $\eta$. It appears that $\eta$ is constant for all age groups, except for the youngest age category, where $\eta$ is statistically not different from zero. Re-estimating the model excluding the youngest age category does not affect any of the conclusions. Finally, we have estimated a range of different hazard rate models (e.g., the Weibull model) and models including unobserved heterogeneity (using the gamma mixing distribution), but the estimate remains robust. ${ }^{21}$

\subsection{Moves to renting revisited}

Our estimation procedure relies on the distinction between moves to renting and to ownership. Due to imperfect information, 'forced moves' etc, it is expected that some households move to renting for a short period and then move back to owning. One expects that these moves are less (or even not) affected by transaction costs. Our data for the Netherlands indicate that $54 \%$ of the households, that move to renting, move back to

\footnotetext{
${ }^{18}$ Recall, in the Netherlands, transaction tax is equal to $6 \%$; estate agent is equal to $1.85 \%$.

${ }^{19}$ Note further that if we assume that $\beta+\gamma$ is equal to 0.12 (the value reported by the OECD, 1999) and we estimate $\gamma$ the results are almost identical to the reported results.

${ }^{20}$ This result is in line with the housing demand study by Dynarski, 1985, who provides evidence that coefficient differences between movers and non movers are small for non-demographic variables.

${ }^{21}$ In contrast to studies of job mobility, studies of residential mobility for the Netherlands generally find that modelling unobserved heterogeneity does not affect the results. In contrast, Kan (2000) indicates that modelling unobserved heterogeneity may be useful in the US.
} 
ownership within a period of one to seven years. ${ }^{22} 23$ A priori, one expects that the effect of transaction costs on moving to renting permanently is higher (because it excludes moves which are plausibly unrelated to transaction costs). We have re-estimated the residential hazard model, the only difference being that observations of households that move to renting and back to owning before the end of the observation period are censored at the moment of moving to renting. As can be seen from the last column of Table 5, transaction costs have a somewhat stronger negative effect on those moving to renting 'permanently'. Moreover, the results indicate that the effect on moving to renting 'permanently' is stronger than to ownership (in line with empirical studies in the US). In conclusion, in line with theoretical considerations, our estimates imply that the marginal effects of transaction costs are higher for voluntary residential mobility than for residential mobility in general.

\section{Table 6 over here}

\section{Conclusion}

In conclusion, in this paper we have estimated the effect of transaction costs on residential mobility. Our estimates indicate that a one percent-point decrease in transaction taxes (as a percentage of the property value) increases mobility to ownership by about $8 \%$. For the Netherlands, this estimate implies that abolition of the six percent buyers' transaction tax induces an increase in the residential mobility rate from ownership to ownership by about $50 \%$. Of course, abolition of transaction tax also effects renters. We can only speculate about the effect on renters. Nevertheless, since a large share of renters will not move to owning for reasons which are not related to transaction costs, it is likely that the abolition of the buyer tax has a smaller effect on the population of renters. As in any microeconomic study, our estimates ignore any macroeconomic effects. In the current context, the study by Lundborg and Skedinger (1998), which employs a housing market equilibrium search model in the spirit of Wheaton (1990), is relevant, since it indicates that a decrease in buyer transaction costs increases equilibrium house prices only slightly suggesting that our estimates are robust with

\footnotetext{
${ }^{22}$ Similarly, in the United States, about $50 \%$ of households which move to renting move back to ownership within 5 years (Clark and Dieleman, 1996).

${ }^{23}$ In our data, moves are measured only once a year, so households that move to renting and back to owning within a year are treated as moves to owning.
} 
respect to major changes in the transaction costs. To what extent our estimates for the Netherlands can be generalized to other countries remains open to debate. ${ }^{24}$

\footnotetext{
${ }^{24}$ In this respect, the results by Schneider et al. (1985) are not too encouraging. They show that differences in estimates of residential mobility determinants between two OECD countries (USA and West Germany) are sometimes substantial.
} 


\section{References}

AGV (1995), The effects of fiscal measures on mobility, housing market and labour market, mimeo.

Amundsen, E. (1985) Moving costs and the microeconomics of intra-urban mobility, Regional Science and Urban Economics, 15, 573-583.

Boehm, T.P. (1981), Tenure choice and expected mobility: a synthesis, Journal of Urban Economics, 10, 375-389.

Chan, S. (1996), Residential mobility and mortgages, Regional Science and Urban Economics, $26,287-311$.

Clark, W.A.V. en S.D. Withers (1999), Changing jobs and changing houses: mobility outcomes of employment transitions, Journal of Regional Science, 39, 653-673.

Clark, W.A.V. and F.M. Dieleman (1996), Households and housing: choice and outcome in the housing market, Rutgers, New Yersey.

Charlier, E.B., B. Melenberg, and A.H.O. van Soest (2000), An analysis of housing expenditure using semiparametric cross-section models, Empirical Economics, 25, 437-462 .

Charlier, E.B., B. Melenberg, and A.H.O. van Soest (2001), An analysis of housing expenditure using semiparametric models and panel data, Journal of Econometrics, 101, 71-107.

Dieleman, F.M., W.A.V. Clark, and M.C. Deurloo (1995), Falling out of the home owner market, Housing Studies, 10, 3-15.

Dynarski, M. (1985), Housing demand and disequilibrium, Journal of Urban Economics, $42-57$.

Edin, P. and P. Englund (1991), Moving costs and housing demand: Are recent movers really in equilibrium?, Journal of Public Economics, 44, 299-350.

Englund, P. (1985), Taxation of capital gains on owner-occupied homes: ? accrual versus realization, European Economic Review, 279, 311-334.

Everaers, P.C. and Davies, S. (1993), Verhuizen in Nederland in de jaren tachtig, Maandstatistieken Bouw CBS , 93/12, 5-26.

Ginsberg, R.B. (1979a), Timing and duration effects in residence histories and other longitudinal data; I stochastic and statistical models, Regional Science and Urban Economics, 9, 311-331.

Ginsberg, R.B. (1979b), Timing and duration effects in residence histories and other longitudinal data; II studies of duration effects in Norway, 1965-1971, Regional 
Science and Urban Economics, 9, 369-392.

Goldberger, A.S. (1991), A course in econometrics, Harvard University Press, Cambridge, Massachusetts.

Gronberg, T.J. and W.R. Reed (1992), Estimation of duration models using the Annual Housing Survey, Journal of Urban Economics, 31, 311-324.

Hanushek, E. and J. Quigley (1978), An explicit model of intra-metropolitan mobility, Land Economics, 54, 410-429.

Hardman A.M. and Y.M. Ioannides (1995), Moving behaviour and the housing market, Regional Science and Urban Economics, 25, 21-39.

Haurin, D. R. and H. L. Grill (1987), Effects of income variability on the demand for owneroccupied housing, Journal of Urban Economics, 136-150.

Haurin, D. R. and H. L. Grill (2002), The impact of transaction costs and the expected length of stay on homeownership, Journal of Urban Economics, 51, 563-584.

Henderson, J.V. and Y.M. Ioannides (1987), Owner occupancy: investment vs. consumption demand, Journal of Urban Economics, 21, 228-241.

Henderson, J.V. and Y.M. Ioannides (1989), Dynamic aspects of consumer decisions in housing markets, Journal of Urban Economics, 26, 212-230.

Ihlanfeldt, K. and J. Siberman (1985), Differential response to change: the case of home purchase, Journal of Urban Economics, 127-144.

Ioannides, Y.M. and S.S. Rosenthal (1994), Estimating the consumption and investment demands for housing and their effect on housing tenure status, The Review of Economics and Statistics, 76, 127-141.

Ioannides, Y.M. and K. Kan (1996), Structural estimation of residential mobility and housing tenure choice, Journal of Regional Science, 36, 3, 335-364.

Kan, K. (2000), Dynamic modelling of housing tenure choice, Journal of Urban Economics, $48,1,46-49$.

Lancaster, T. (1979), Econometric methods for the duration of unemployment, Econometrica, 47, 939-956.

Lancaster, T. (1990), The econometric analysis of transition data, Cambridge University Press, Cambridge.

Lundborg, P. and P. Skedinger (1998), Transaction taxes in a search model of the housing market, Journal of Urban Economics, 45, 385-399.

Lundborg, P. and P. Skedinger (1999), Capital gains , taxation and residential mobility in Sweden, Journal of Public Economics, 67, 393-419. 
Maddala, G.S. (1983), Limited-dependent and qualitative variables in econometrics, Econometric Society Monographs.

Mizon, G.E. and R. Richard (1986), The encompassing principle and its application to testing non-nested hypotheses, Econometrica, 54, 657-678.

OECD (1999), Denmark, 3, OECD, Paris.

O’Sullivan, A., T.A. Sedon and S.M. Sheffin (1995), Property taxes, mobility, and homeownership, Journal of Urban Economics, 37, 107-129.

Oswald, A.J. (1997), The missing piece of the unemployment puzzle: An inaugural lecture, mimeo.

Oswald, A.J. (1999) The housing market and Europe's unemployment: a non-technical paper, mimeo University of Warwick.

Quigley, J.M. (1987), Interest rate variations, mortgage prepayments and household mobility, Review of Economics and Statistics, 69,4, 636-643.

Robinson, R. (1988), Urban housing finance, OECD, Paris.

Rosenthal, S.S. (1988), A residence time model of housing markets, Journal of Public Economics, 36, 87-109.

Rouwendal, J. and E. Meijer (2001), Preferences for housing, jobs, and commuting: a mixed logit analysis, Journal of Regional Science, 41, 3, 475-505.

Schneider, W., K. Stahl and R.J. Struyk (1985), Residential mobility in the United States and the Federal Republic of Germany, in: Stahl, K. and R.J. Struyk (eds.), U.S. and West German housing markets, Springer Verlag, Berlin.

Van der Vlist, A.J., C. Gorter, P. Nijkamp and P. Rietveld (2002), Residential mobility and local housing-market differences, Environment and Planning A, 34, 1147-1164.

Van Ommeren, J.N., P. Rietveld and P. Nijkamp (2000), Job mobility, residential mobility, and commuting: a theoretical analysis using search theory, Annals of Regional Science, 34, 213-232.

Van Vuuren, A. (2002), Empirical analysis of search using novel types of data, Tinbergen Institute Research Series, Amsterdam.

Venti, S.F. and D.A. Wise (1984), Moving and housing expenditure: transaction costs and disequilibrium, European Economic Review, 207-243.

Weinberg, O.H., J. Friedman and S.K. Mayo (1981), Intraurban residential mobility: the role of transaction costs, market imperfections, and household disequilibrium, Journal of Urban Economics, 9, 332-348.

Wheaton, W. (1990), Vacancy, search, and prices in a housing market matching 
model, Journal of Political Economy, 98, 1270-1292. 


\section{Appendix 1}

\section{Figure 1 Residential mobility and transaction costs.}

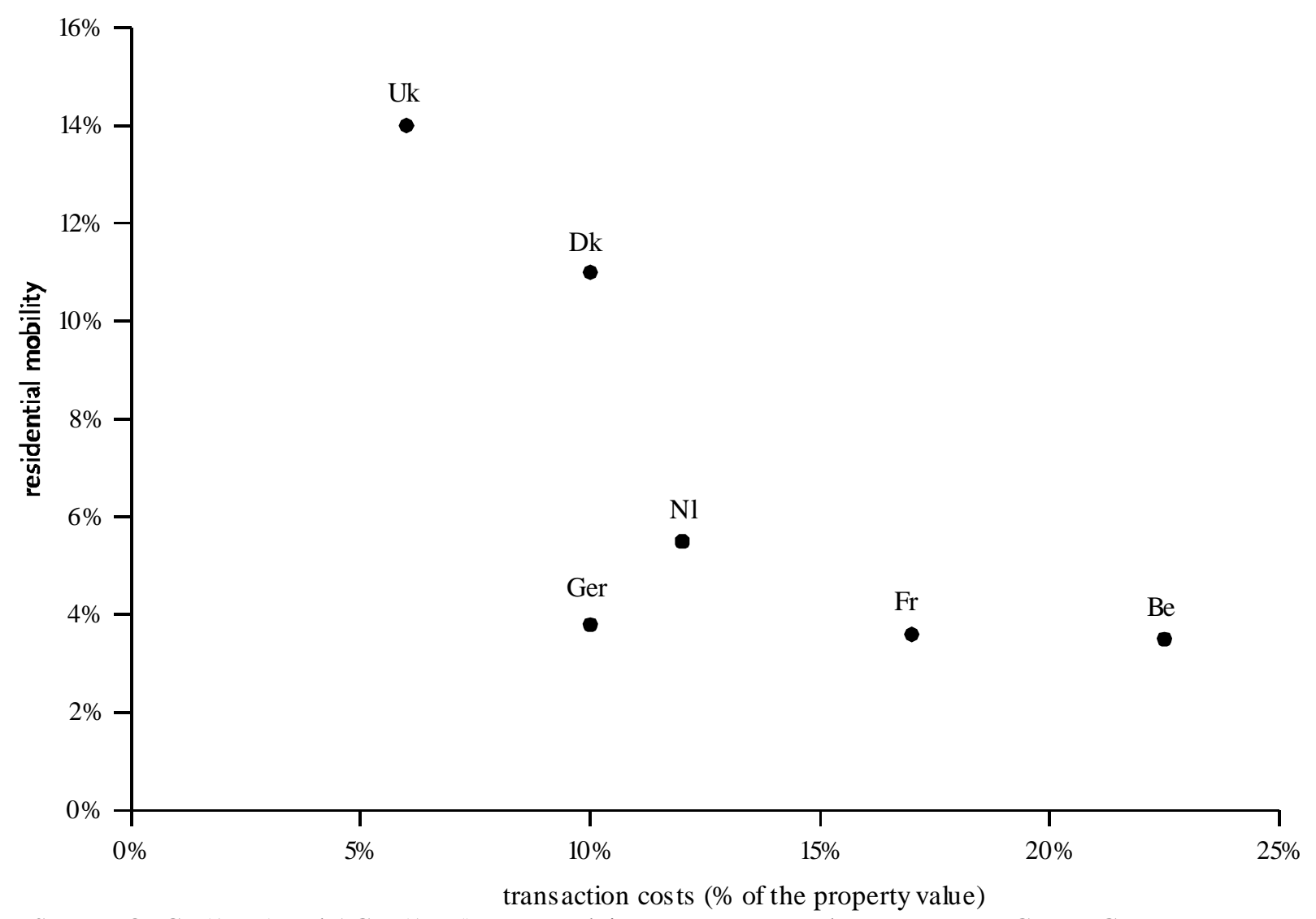

Source: OECD(1999) and AGV (1995), BE = Belgium, DK = Denmark, FR = France, GER = Germany, NL = the Netherlands, UK = United Kingdom

Note: Residential mobility is defined as the number of owners' moves divided by the number of owners. A regression of (the logarithm of) residential mobility on transaction costs gives an 8 percent decrease in residential mobility given a one percent-point increase in transaction costs $\left(\mathrm{R}^{2}=0.60 ; \mathrm{t}\right.$-value $\left.=2.43\right)$. 
Table 1. Marginal effects of transaction costs on moving to ownership and to renting.

1. Assumptions: perfect foresight; $\beta, \eta$ and $\gamma$ are known.

$$
\frac{\partial P^{o}}{\partial m}=\frac{1}{\beta+\eta \gamma} \frac{d P^{o}}{d V} \quad \frac{\partial P^{r}}{\partial m}=\frac{1}{\beta} \frac{d P^{r}}{d m}
$$

\section{Assumptions:}

(a) perfect foresight; $\eta$ and $\gamma$ are known; $\frac{\partial P^{r}}{\partial m}=\frac{\partial P^{o}}{\partial m}$

or

(b) $\eta$ and $\gamma$ are known; $\frac{\partial P^{r}}{\partial m}=\frac{\partial P^{o}}{\partial m} ; \frac{\partial P^{r}}{\partial V}=\frac{\partial P^{o}}{\partial V}$.

$$
\frac{\partial P^{o}}{\partial m}=\frac{\partial P^{r}}{\partial m}=\frac{\frac{d P^{o}}{d V}-\frac{d P^{r}}{d V}}{\eta \eta} \quad \text { and } \quad \beta=\frac{\eta \gamma \frac{d P^{r}}{d V}}{\frac{d P^{o}}{d V}-\frac{d P^{r}}{d V}}
$$


Table 2. Description of variables.

\begin{tabular}{|l|r|r|}
\hline & Mean & Standard Deviation \\
\hline Duration in years (including incomplete spells) & 4.3007 & 2.11 \\
Move to ownership & 0.047 & 0.21 \\
Move to the renting & 0.11 & 0.31 \\
Female & 0.50 & 0.50 \\
Working partner & 0.48 & 0.50 \\
One-person household & 0.12 & 0.33 \\
Two person household & 0.44 & 0.47 \\
Less than 25 years of age & 0.12 & 0.33 \\
25-35 years of age & 0.35 & 0.48 \\
35-45 years of age & 0.22 & 0.42 \\
$45-55$ years of age & 0.15 & 0.36 \\
Savings dummy & 0.06 & 0.39 \\
Household income (in logarithm) & 9.99 & 0.53 \\
Value of mortgage as a share of the value of the residence & 0.58 & 0.236 \\
Value of residence (in 100,000 euros) & 0.87 & 0.46 \\
Value of next residence (in 100,000 euros) & 0.33 \\
Urban environment & & 0.45 \\
\hline
\end{tabular}


Table 3A. Competing risks residential mobility hazard model: moves to renting and ownership

\begin{tabular}{|c|c|c|c|c|}
\hline & Estimates & Std. error & Estimates & Std. error \\
\hline & \multicolumn{2}{|c|}{ Moves to renting } & \multicolumn{2}{|c|}{ Moves to ownership } \\
\hline Value of residence & -0.1078 & 0.0616 & $-0.8426^{*}$ & 0.1034 \\
\hline Less than 25 years & 0.019 & 0.104 & -0.003 & 0.163 \\
\hline $25-35$ years & -0.068 & 0.087 & 0.011 & 0.132 \\
\hline $35-45$ years & 0.093 & 0.089 & 0.002 & 0.138 \\
\hline $45-55$ years & 0.099 & 0.088 & 0.139 & 0.133 \\
\hline Female & $0.293^{*}$ & 0.050 & 0.134 & 0.075 \\
\hline Working partner & $-0.257^{*}$ & 0.059 & -0.096 & 0.089 \\
\hline One-person household & -0.023 & 0.087 & -0.100 & 0.140 \\
\hline Two person household & -0.052 & 0.059 & -0.111 & 0.088 \\
\hline Savings dummy & 0.006 & 0.104 & 0.312 & 0.148 \\
\hline $\begin{array}{l}\text { Household income in } \\
\text { logs }\end{array}$ & -0.070 & 0.061 & 0.430 & 0.101 \\
\hline Urban environment & $0.122 *$ & 0.057 & $0.257 *$ & 0.085 \\
\hline $\begin{array}{l}\text { Value of the mortgage/ } \\
\text { value of the residence }\end{array}$ & $-0.362 *$ & 0.064 & $-0.284 *$ & 0.095 \\
\hline Regional dummies (40) & Yes & & Yes & \\
\hline Year dummies (6) & Yes & & Yes & \\
\hline Number of observations & 16090 & & 16090 & \\
\hline Log likelihood & -15847.90 & & -6937.06 & \\
\hline $\begin{array}{l}\text { *) significant at the } 1 \%- \\
\text { level }\end{array}$ & & & & \\
\hline
\end{tabular}


Table 3B. Competing risks residential mobility hazard model: moves to renting and ownership

\begin{tabular}{|c|c|c|c|c|}
\hline & Estimates & Std. error & Estimates & Std. error \\
\hline & \multicolumn{2}{|c|}{ Moves to renting } & \multicolumn{2}{|c|}{ Moves to ownership } \\
\hline $\begin{array}{l}\text { Value of residence in } \\
\operatorname{logs}\end{array}$ & -0.305 & 0.047 & $-0.726^{*}$ & 0.067 \\
\hline Less than 25 years & 0.013 & 0.104 & -0.017 & 0.163 \\
\hline $25-35$ years & -0.045 & 0.087 & 0.027 & 0.132 \\
\hline $35-45$ years & 0.130 & 0.089 & 0.010 & 0.138 \\
\hline $45-55$ years & 0.121 & 0.088 & 0.143 & 0.133 \\
\hline Female & $0.294 *$ & 0.050 & 0.139 & 0.075 \\
\hline Working partner & $-0.242 *$ & 0.060 & -0.072 & 0.089 \\
\hline One-person household & -0.027 & 0.088 & -0.131 & 0.140 \\
\hline Two person household & -0.031 & 0.059 & -0.103 & 0.087 \\
\hline Savings dummy & 0.049 & 0.104 & $0.330^{*}$ & 0.148 \\
\hline $\begin{array}{l}\text { Household income in } \\
\operatorname{logs}\end{array}$ & 0.015 & 0.062 & $0.447 *$ & 0.099 \\
\hline Urban environment & 0.088 & 0.058 & $0.227 *$ & 0.086 \\
\hline $\begin{array}{l}\text { Value of the mortgage/ } \\
\text { value of the residence }\end{array}$ & $-0.361 *$ & 0.064 & $-0.225^{*}$ & 0.094 \\
\hline Regional dummies (40) & Yes & & Yes & \\
\hline Year dummies (6) & Yes & & Yes & \\
\hline Number of observations & 16090 & & 16090 & \\
\hline Log likelihood & -16092.11 & & -6923.15 & \\
\hline $\begin{array}{l}\text { *) significant at the } 1 \% \text { - } \\
\text { level }\end{array}$ & & & & \\
\hline
\end{tabular}


Table 4 Estimation of relationship between value of current and next residence

\begin{tabular}{|l|c|c|}
\hline & Estimates & Std. error \\
\hline Explanatory variable & & 0.07 \\
\hline Value of residence & $0.58^{*}$ & 0.13 \\
\hline Less than 25 years & 0.11 & 0.10 \\
\hline 25-35 years & $0.33^{*}$ & 0.10 \\
\hline 35-45 years & $0.38^{*}$ & 0.10 \\
\hline 45-55 years & 0.12 & 0.06 \\
\hline Female & 0.11 & 0.07 \\
\hline Working partner & -0.12 & 0.11 \\
\hline One-person household & 0.21 & 0.07 \\
\hline Two person household & -0.02 & 0.12 \\
\hline Savings dummy & $0.33^{*}$ & 0.07 \\
\hline Real household income in log & $0.34^{*}$ & 0.07 \\
\hline Urban environment & -0.02 & \\
\hline Value of the mortgage/ value of & -0.10 & \\
\hline the residence & & \\
\hline Regional dummies (40) & Yes & \\
\hline Year dummies (6) & 679 & \\
\hline & 0.345 & \\
\hline Number of observations & & \\
\hline $\mathrm{R}^{2}$ & & \\
\hline$*$ significant at the 1\%-level & & \\
\hline & & \\
\hline Note: Dependent variable is the valtent & \\
\hline
\end{tabular}

Note: Dependent variable is the value of the next residence; the values of current and next residence are in 100000 euros. 
Table 5. The effect of a one percent-point increase in the transaction costs on the percentage change in the (competing risks) residential mobility rate.

Specification $1(\beta=0.03 ; \gamma=0.09)$

Move to ownership

linear

$-8.36$

(1.77)

loglinear

$-8.76$

(1.24)

Specification $2(\gamma=0.09)$

linear

$-11.44$

(1.29)

loglinear

$-8.05$

(1.39)
Move to renting

$-$

$-12.66$

(2.04)

\section{Move to}

'permanent' renting

$-12.04$

(3.21)

$-21.10$

(3.03)

estimated $\beta$

$\begin{array}{ll}-11.44 & 0.00061 \\ (1.29) & (0.00045) \\ -8.05 & 0.037 \\ (1.39) & (0.005)\end{array}$

Note: standard error in parentheses. Standard errors are calculated using the delta method (e.g., Goldberger, 1991). The effects based on the linear model are evaluated at the mean property value. 
Table 6. Residential mobility hazard model: permanent moves to renting.

\begin{tabular}{|c|c|c|c|c|}
\hline & Estimates & Std. error & Estimates & Std. error \\
\hline & \multicolumn{2}{|c|}{ Moves to renting } & \multicolumn{2}{|c|}{ Moves to renting } \\
\hline Value of residence & $-0.385^{*}$ & 0.0935 & - & \\
\hline $\begin{array}{l}\text { Value of residence in } \\
\text { logs }\end{array}$ & - & & $-0.500^{*}$ & 0.069 \\
\hline Less than 25 years & 0.088 & 0.142 & 0.081 & 0.142 \\
\hline $25-35$ years & -0.169 & 0.127 & -0.143 & 0.127 \\
\hline $35-45$ years & -0.187 & 0.137 & -0.152 & 0.136 \\
\hline $45-55$ years & -0.174 & 0.136 & -0.157 & 0.136 \\
\hline Female & $0.366^{*}$ & 0.075 & $0.370^{*}$ & 0.075 \\
\hline Working partner & $-0.235^{*}$ & 0.091 & $-0.212 *$ & 0.091 \\
\hline One-person household & -0.018 & 0.125 & -0.036 & 0.126 \\
\hline Two person household & -0.024 & 0.090 & -0.007 & 0.089 \\
\hline Savings dummy & -0.262 & 0.179 & -0.221 & 0.179 \\
\hline $\begin{array}{l}\text { Household income in } \\
\operatorname{logs}\end{array}$ & $-0.359^{*}$ & 0.081 & $-0.301 *$ & 0.084 \\
\hline Urban environment & $0.239 *$ & 0.086 & $0.196 *$ & 0.086 \\
\hline $\begin{array}{l}\text { Value of the mortgage/ } \\
\text { value of the residence }\end{array}$ & $-0.330^{*}$ & 0.095 & $-0.308 *$ & 0.094 \\
\hline Regional dummies (40) & Yes & & Yes & \\
\hline Year dummies (6) & Yes & & Yes & \\
\hline Number of observations & 16090 & & 16090 & \\
\hline Log likelihood & -7033.79 & & -7017.31 & \\
\hline $\begin{array}{l}\text { *) significant at the } 1 \% \text { - } \\
\text { level }\end{array}$ & & & & \\
\hline
\end{tabular}

